\title{
RESENHA DAS NOTAS TÉCNICAS EVITANDO A PANDEMIA DA POBREZA: POSSIBILIDADES PARA O PROGRAMA BOLSA FAMIILIA E PARA O CADASTRO ÚNICO EM RESPOSTA À COVID-19 E ESTIMATIVAS DE PÚBLICO ELEGÍVEL E CUSTOS DO BENEFÍCIO EMERGENCIAL CRIADO PELO PL No 9.236/2017
}

Rafael Leão

Este texto é uma resenha de:

Paiva, L. H., ${ }^{2}$ Souza, P. H. G., ${ }^{3}$ Bartholo, L.; ${ }^{4}$ Soares, $S .{ }^{5}$ Evitando a Pandemia da Pobreza: possibilidades para o Programa Bolsa Familia e para o Cadastro Único em resposta à Covid-19. Brasilia: Ipea, 2020.

(Nota Técnica, n. 59). Disponivel em: <https://bit.ly/2Khefyd>.

Paiva, L. H.; Souza, P. H. G.; Bartholo, L.; Soares, S. Estimativas de Público Elegível e Custos do Benefício Emergencial Criado pelo PL no 9.236/2017. (Nota Técnica, n. 60). Disponivel em: <https://bit.ly/2RANIQ8>.

\section{SINOPSE}

Para subsidiar o governo federal no entendimento dos caminhos a serem tomados para enfrentar a crise social causada pela Covid-19, a Disoc publicou duas notas técnicas (no 59 e no 60 ) sugerindo possíveis açóes a serem implementadas no curto prazo, com indicações da relação custo-benefício entre as dificuldades institucionais e operacionais, o custo fiscal e os benefícios para a população. Esta resenha tem o mero objetivo de consolidar as principais análises e resultados desses esforços, permitindo que as mensagens de ambas as notas técnicas alcancem um público ainda maior.

Palavras-chave: pandemia; coronavírus; Covid-19; Bolsa Família; Cadastro Único; ajuda emergencial.

\section{INTRODUÇÃO}

Desde o início da crise da Covid-19, sabe-se que o país seria acometido por dois grandes choques: um de origem sanitária e outro de origem econômica. As medidas de isolamento social e de fechamento e interrupção de diversas atividades econômicas, necessárias para conter o avanço da epidemia em território brasileiro, colocaram enorme parcela da população economicamente ativa em risco de desemprego, desocupação, ou mesmo causaram perdas expressivas de rendimento monetário.

Os trabalhadores informais e as populaçóes tradicionalmente mais vulneráveis do país subitamente vislumbraram um cenário de dificuldades econômico-financeiras ainda maiores. ${ }^{6}$ Medidas de ajuda financeira

\footnotetext{
1. Especialista em políticas públicas e gestão governamental na Diretoria de Estudos e Políticas Setoriais de Inovação e Infraestrutura (Diset) do Ipea e editor deste Radar.

2. Especialista em políticas públicas e gestão governamental em exercício na Diretoria de Estudos e Políticas Sociais (Disoc) do Ipea.

3. Técnico de planejamento e pesquisa na Disoc/lpea.

4. Especialista em políticas públicas e gestão governamental em exercício na Disoc/lpea.

5. Técnico de planejamento e pesquisa na Disoc/lpea.

6. Disponível em: <https://glo.bo/3beNiae>.
} 
emergencial para essas populaçóes tornaram-se o assunto central no debate sobre as açóes do Estado brasileiro para conter as consequências socioeconômicas que se abaterão sobre a economia do país.

Para subsidiar o governo federal no entendimento dos possíveis caminhos a serem tomados, a Disoc publicou a Nota Técnica no 59 no dia 27 de março, sugerindo possíveis açóes a serem implementadas no curto prazo, com indicaçôes da relaçáo custo-benefício entre as dificuldades institucionais e operacionais, o custo fiscal e os benefícios para a população.

Naquele mesmo momento, o Projeto de Lei (PL) no 9.236/2017 foi aprovado pela Câmara dos Deputados e se encaminhava para aprovaçáo no Senado Federal. Esse PL alterou critérios de concessão do Benefício de Prestação Continuada (BPC) e instituiu auxílio emergencial aos trabalhadores informais, autônomos, microempreendedores individuais e desempregados. A Disoc, entáo, publicou, no dia $1^{\circ}$ de abril, a Nota Técnica nº 60, que apresenta uma estimativa dos benefícios para a populaçáo e dos custos para o Estado da aprovaçáo dessa medida.

Este texto tem o mero objetivo de consolidar as principais análises e resultados desses esforços, permitindo que as mensagens de ambas as notas técnicas alcancem um público ainda maior.

\section{A NOTA TÉCNICA № 59}

A primeira nota técnica debateu possíveis cenários e critérios concretos de intervençáo, tendo como pontos de partida o Programa Bolsa Família (PBF) e o Cadastro Único para Programas Sociais (Cadastro Único):

a) zerar a fila do PBF e postergar os processos de averiguação e revisáo cadastral, de maneira a permitir que as famílias já cadastradas e as que estão na fila de espera já recebam o benefício de maneira imediata, além de evitar que as pessoas se dirijam aos centros de referência em assistência social (Cras), atendendo a condicionantes sanitárias de não aglomeração de pessoas;

b) reajustar a linha de elegibilidade e o valor dos beneficios do $P B F$, atualizando os valores pagos;

c) criar um beneficio extraordinário por pelo menos seis meses para todas as famílias do PBF, pelo agravamento da situação de vulnerabilidade social trazida pela pandemia; e

d) criar um beneficio extraordinário por pelo menos seis meses para todas as familias do Cadastro Único com renda familiar per capita de até meio salário minimo. Essa proposta incluiria beneficiários e não beneficiários do Bolsa Família.

As simulações foram feitas a partir da combinação das quatro propostas elencadas acima. Primeiramente, analisaram-se os impactos fiscais, os benefícios para a população, os desafios institucionais e operacionais da medida $a$; em seguida, esses critérios foram utilizados para se avaliar a simulaçáo das combinaçôes possíveis entre a medida $a$ e três variaçôes possíveis da medida $b$; posteriormente, foi feita a avaliaçáo da combinação da medida $a$ com as três variaçôes da medida $b$ e mais duas variações possíveis da medida $c$.

No caso da medida $d$, sua análise foi acumulada apenas com as medidas $a$ e $b$ porque na prática ela seria uma extensão da medida $c$, visto que o grupo de pessoas do PBF está incluído no universo de pessoas do Cadastro Único. Vale pontuar que todas as combinaçóes possíveis, com o número de pessoas e famílias beneficiadas, bem como os valores recebidos, também por pessoa e por família, estão devidamente descritos na Nota Técnica no ${ }^{59}$; o número de combinaçóes possíveis entre as quatro linhas de ação totaliza 72.

As análises e simulaçóes foram conduzidas dessa maneira para contemplar diversas linhas de ação que partissem de desafios institucionais e operacionais mais triviais, mas de alcance social mais limitado e reduzido impacto fiscal, até linhas de ação com maiores complexidades institucionais e operacionais, porém que se traduzissem em maiores benefícios à população potencialmente atingida - e maiores impactos fiscais, consequentemente. 
Longe de se descreverem todas as combinações - o que nem mesmo a própria nota técnica se propôs a fazer -, vale destacar alguns pontos. A linha de ação com praticamente nenhum desafio institucional, medida a, representaria um custo fiscal de apenas $\mathrm{R} \$ 2,24$ bilhões no exercício fiscal de 2020 , além dos atuais $\mathrm{R} \$ 23,2$ bilhôes que custaria o PBF entre a publicação da nota (abril) e o mês de dezembro. O número de pessoas e famílias atendidas sairia dos atuais 42,7 milhóes de pessoas e 13,8 milhóes de famílias para 47,7 milhóes de pessoas e 15,5 milhões de famílias. O benefício médio por família permaneceria praticamente inalterado: de R\$188 para $\mathrm{R} \$$ 183. O desafio operacional estaria em garantir que aproximadamente 1,7 milhão de cartóes do PBF fossem emitidos e alcançassem as famílias da fila de espera em tempo recorde, pela urgência da crise.

No outro extremo estaria a combinaçáo das medidas $a, b$ e $d$. Ou seja: zerar a fila do PBF com reajuste dos valores dos benefícios pagos (29\%, no exemplo dado aqui) e criar um benefício adicional por família de R $\$ 450$ por pelo menos seis meses para as famílias com renda per capita mensal de até meio salário mínimo. Essa é a recomendação de ação emergencial dos próprios autores.

Nesse caso, a medida geraria um custo fiscal adicional para 2020 de R \$ 68,6 bilhóes, mas os benefícios sociais seriam largamente potencializados. O número de pessoas e famílias alcançadas seria de 63,6 milhóes e 21,1 milhões, respectivamente, e o benefício médio por família sairia dos atuais $\mathrm{R} \$ 188$ para $\mathrm{R} \$ 633$.

Ainda que o custo fiscal seja praticamente quadruplicado neste que seria o cenário mais generoso, os $\mathrm{R} \$ 91,9$ bilhôes que custariam toda a ação - que inclui os $\mathrm{R} \$ 23,2$ bilhôes que já seriam regularmente gastos no PBF entre abril e dezembro de 2020 - representariam apenas menos de 1,3\% do produto interno bruto (PIB), tendo 2019 como referência. Como boa parte dessa linha de ação seria temporária, o impacto fiscal adicional, em proporção do PIB em 2021, seria de apenas 0,2\% - fruto dos ajustes no PBF, que, esses sim, teriam efeitos duradouros.

\section{A NOTA TÉCNICA № 60}

Enquanto a Nota Técnica no 59 estava sendo elaborada e enviada para publicação, o Congresso Nacional aprovava o PL n⿳⺈ 9.236/2017, que instituiu um auxílio emergencial de $\mathrm{R} \$ 600$ a ser pago durante três meses para trabalhadores que atenderem aos critérios a seguir.

I. Forem maiores de 18 anos.

II.Não tenham emprego formal.

III. Não sejam beneficiários de outros programas assistenciais ou previdenciários, com exceção exclusiva ao PBF.

IV.Tenham renda domiciliar per capita de até meio salário mínimo ou renda total de até três salários mínimos.

V. Tenham recebido rendimentos tributáveis de no máximo R 28.559,70 em 2018.

VI. Exerçam atividade na condição de microempreendedor individual (MEI), ou sejam contribuintes individuais do Regime Geral de Previdência Social (RGPS), ou ainda sejam trabalhadores informais ou desempregados.

A equipe da Disoc, então, tentou estimar os impactos do PL do ponto de vista do benefício social e do custo fiscal. A estratégia estatística envolveu, basicamente, uma análise dos microdados da Pesquisa Nacional por Amostra de Domicílios (PNAD) Contínua de 2018, pois parte relevante do público potencialmente beneficiário não está inscrita no Cadastro Único. Aqui está, de fato, o grande desafio de efetividade dessa medida: alcançar pessoas virtualmente invisíveis aos cadastros oficiais do governo.

Criando cenários distintos de efetividade, a simulação dos impactos trabalhou com níveis distintos de alcance dessas populaçóes que estão à margem do Cadastro Único. Foram três cenários: dois mais extremos (e também mais improváveis), um de alcance de $100 \%$, outro de alcance de $0 \%$ do público não inscrito no Cadastro Único; e um intermediário, de alcance de $50 \%$ desse público. 
Com base nos critérios de elegibilidade elencados anteriormente e nas interpretaçóes cadastrais e estatísticas da PNAD Contínua, o trabalho encontrou um público-alvo elegível de 59,2 milhóes de pessoas. Destas, 81,7\% são mais facilmente identificáveis, pois estão inscritas no Cadastro Único. As demais 10,9 milhóes são pessoas que podem se enquadrar em uma de quatro categorias:

- MEIs ou contribuintes individuais;

- trabalhadores por conta própria;

- empregados informais; e

- pessoas sem ocupação.

As estimativas de número de pessoas e famílias beneficiadas, o benefício médio e o custo fiscal estão na tabela 1.

\section{TABELA 1}

Número de pessoas e de famílias beneficiadas, benefício médio e custo fiscal

\begin{tabular}{|c|c|c|c|c|c|c|}
\hline & \multicolumn{2}{|c|}{ População afetada direta ou indiretamente (milhóes) } & \multicolumn{2}{|c|}{ Benefício médio $(\mathrm{R} \$)$} & \multicolumn{2}{|c|}{ Despesa ( $\mathrm{R}$ \$ bilhōes) } \\
\hline & Famílias & Pessoas & Famílias & Pessoas & Total & Adicional \\
\hline \multicolumn{7}{|c|}{ Cenário atual ${ }^{1}$} \\
\hline PBF & 9,7 & 38,6 & 183 & 46 & 5,3 & - \\
\hline \multicolumn{7}{|c|}{ Simulaçôes com diferentes graus de cobertura dos elegíveis não inscritos no Cadastro Único ${ }^{2}$} \\
\hline $0 \%$ & 27,6 & 93,6 & 966 & 285 & 80,1 & 74,8 \\
\hline $50 \%$ & 32,5 & 107,2 & 924 & 280 & 90,1 & 84,8 \\
\hline $100 \%$ & 36,4 & 117,5 & 913 & 283 & 99,6 & 94,3 \\
\hline
\end{tabular}

Fonte: Microdados da PNAD Contínua de 2018.

Notas: ${ }^{1}$ Os números do PBF estáo subestimados em comparação com os registros administrativos. Não fizemos nenhuma correção para isso. Em 2018, o número médio de famílias beneficiárias ficou próximo de 14 milhōes.

${ }^{2}$ Participação no Cadastro Único imputada para famílias beneficiárias do PBF, indivíduos beneficiários do BPC e famílias com renda mensal per capita de fontes formais menor ou igual a meio salário mínimo.

De qualquer maneira, vale aqui a notificação dessas estimativas para o cenário mais provável dos três apontados logo acima. Assim, no caso de o governo federal alcançar a metade das pessoas elegíveis que estão fora do Cadastro Único, o total de famílias e pessoas beneficiadas seria de 32,5 milhóes e 107,2 milhóes, respectivamente - considerando-se todas as pessoas diretamente beneficiadas ou que residem em lares onde há beneficiários. O benefício médio por família seria de R \$ 924 e o custo fiscal de R \$ 90,1 bilhóes no ano de 2020, o que representaria algo entre $1,0 \%$ e $1,3 \%$ do PIB de 2019.

\section{CONCLUSÃO}

A ajuda emergencial de $\mathrm{R}$ \$ 600 determinada pela aprovação do PL no 9.236/2017 figura como o principal instrumento de ação emergencial, do ponto de vista social, para ampla parcela da população brasileira pobre ou vulnerável à pobreza. O custo fiscal, segundo cálculos apresentados na Nota Técnica no $\mathbf{6}$, seria modesto diante da calamidade pública que se avizinha nos próximos meses.

Não deixa de ser notável que essa ajuda emergencial analisada pela Nota Técnica no 60 se assemelhe bastante às propostas de ação que a mesma equipe da Disoc havia sugerido na Nota Técnica no 59 - objetivamente, as linhas de ação $c$ e $d$. As diferenças residem basicamente nos valores específicos dos benefícios e nos prazos de duração da ajuda emergencial - três meses no caso concreto, contra seis meses na proposta técnica. 

Ipea - Instituto de Pesquisa Econômica Aplicada

\section{Assessoria de Imprensa e Comunicação}

\section{EDITORIAL}

\section{Coordenação}

Reginaldo da Silva Domingos

\section{Assistente de Coordenação}

Rafael Augusto Ferreira Cardoso

\section{Supervisão}

Camilla de Miranda Mariath Gomes

Everson da Silva Moura

\section{Revisão}

Ana Clara Escórcio Xavier

Clícia Silveira Rodrigues

Idalina Barbara de Castro

Olavo Mesquita de Carvalho

Regina Marta de Aguiar

Amanda Ramos Marques (estagiária)

Hellen Pereira de Oliveira Fonseca (estagiária)

Ingrid Verena Sampaio Cerqueira Sodré (estagiária)

Isabella Silva Queiroz da Cunha (estagiária)

\section{Editoração}

Aeromilson Trajano de Mesquita

Cristiano Ferreira de Araújo

Danilo Leite de Macedo Tavares

Herllyson da Silva Souza

Jeovah Herculano Szervinsk Junior

Leonardo Hideki Higa

\section{Capa}

Leonardo Hideki Higa

\section{Imagens da Capa}

Banco Freepik (freepik.com)

\section{Projeto Gráfico}

Renato Rodrigues Bueno

The manuscripts in languages other than Portuguese published herein have not been proofread.

Livraria Ipea

SBS - Quadra 1 - Bloco J - Ed. BNDES, Térreo

70076-900 - Brasília - DF

Tel.: (61) 2026-5336

Correio eletrônico: livraria@ipea.gov.br 

